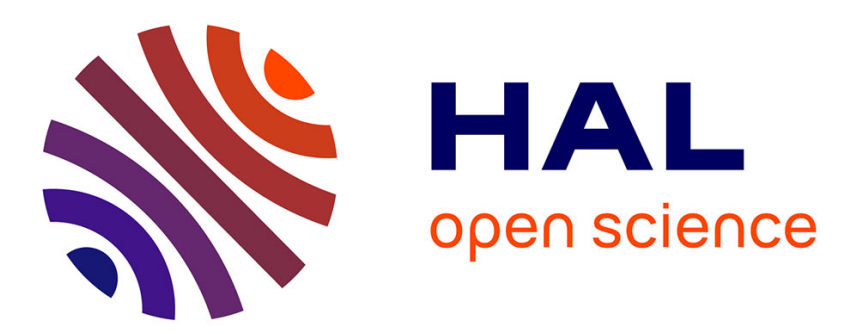

\title{
Efficiency Evaluation of Agricultural Informatization Based on CCR and Super-Efficiency DEA Model
}

\author{
Xu Han, Li Wang, Hui Wang, Shuqin Wang
}

\section{To cite this version:}

Xu Han, Li Wang, Hui Wang, Shuqin Wang. Efficiency Evaluation of Agricultural Informatization Based on CCR and Super-Efficiency DEA Model. 8th International Conference on Computer and Computing Technologies in Agriculture (CCTA), Sep 2014, Beijing, China. pp.240-246, 10.1007/9783-319-19620-6_30. hal-01420239

\section{HAL Id: hal-01420239 \\ https://hal.inria.fr/hal-01420239}

Submitted on 20 Dec 2016

HAL is a multi-disciplinary open access archive for the deposit and dissemination of scientific research documents, whether they are published or not. The documents may come from teaching and research institutions in France or abroad, or from public or private research centers.
L'archive ouverte pluridisciplinaire HAL, est destinée au dépôt et à la diffusion de documents scientifiques de niveau recherche, publiés ou non, émanant des établissements d'enseignement et de recherche français ou étrangers, des laboratoires publics ou privés. 


\title{
Efficiency Evaluation of Agricultural Informatization Based on CCR and Super-efficiency DEA Model
}

\author{
Xu $\mathrm{HAN}^{1, \mathrm{a}}$, Li WANG ${ }^{1, \mathrm{~b}}$,Hui WANG ${ }^{1, \mathrm{c}}$, Shuqin $\mathrm{WANG}^{1, \mathrm{~d}}$ \\ ${ }^{1}$ School of Information Engineering, Minzu University of China, Beijing 100081, China; \\ ahanxu@muc.edu.cn, ${ }^{\mathrm{b}}$ wlry8812@sohu.com, ${ }^{\mathrm{c}}$ wanghui_610919@163.com, ${ }^{\mathrm{d}}$ cd-wx@163.com
}

\begin{abstract}
In this research, we want to evaluate the efficiency of input / output in agricultural informatization (AI) and the redundancy of AI by using DEA method. An index system evaluating the input and output in agricultural informatization was built with the support of CCR Model and Super-efficiency DEA Model, which contains 9 indices. We processed the data of agricultural informatization in Huaihua and Xiangxi, two areas in Hunan province, with DEMP and EMS software and analyzed the efficiency of agricultural informatization in different 5 years and figure out the tendency of developing status in AI from 2009 to 2013. The results show that the CRSTE, VRSTE, SCALE efficiency of AI in two areas is efficient and the inputs and outputs about AI in 2009 and 2011 have spaces of improving. In general, the developing tendency of AI efficiency in two areas is stable in these years even though they are not developed areas in agricultural informatization. The index system of AI evaluation in this research could be better and reliable in future if we get more data and add more indices in it, but it is hard for us now to get more data because of the limitation of incomplete statistical data released by local governments.
\end{abstract}

Keywords: DEA, CCR, efficiency evaluation, informatization

\section{Introduction}

With the development of information communication technologies (ICTs), the trend of informatization is spreading fast on the world. Agricultural informatization is an important component in our information society, and it is the inevitable outcome that modern information technology combines with agricultural interior demand.

Everett Rogers (2000) defines informatization as the process through which new communication technologies are used as means for furthering development as a nation becomes more and more an information society [1]. As a description of the development, informatization refers to the extent of a geographical area, economy or society continues to develop based information and information communication technologies, in other words, it refers to the degree of workforce size enhanced based on the information and information communication technologies [2]. Agricultural Informtization refers to the information communication technologies (ICTs) are comprehensively applied in the fields of agriculture, and penetrating into agricultural production, marketing, consumption, and rural social, economic, technological, and other specific aspects of the whole process [3].

The efficiency evaluation of AI in this research refers to the production inputs benefit which is achieved by calculating indices about the ICTs supporting agriculture and the output in agriculture. The indices needed in evaluation are different from other researches because of the different research aims. 
Methods in informatizaiton measurement and evaluation abroad [4] usually are Machlup method, Porat method, Informatization Index method. The methods above aims to mainly figure out the informatization level of certain society or economy unit, however they do not focus on the efficiency and can't tell whether it is reasonable in input of the indices related with the AI.

Methods in informatizaiton measurement and evaluation in China are Delphi method, Analytic Hierarchy Process (AHP) method, The method for the measurement of informatization level used in China, raised by National Information Center, combines Machlup method and Porat method, and includes 6 factors and 21 indices. [5] These methods above applied in domestic rural or agricultural informatization research mostly play extra effort on measurement of AI and service ability.

Comparing the researches on evaluating the level of AI, development status of AI and service ability of $\mathrm{AI}$, the research on the efficiency of $\mathrm{AI}$ is rare.

Data Envelopment Analysis (DEA) method is seldom used in researches on evaluation of AI, but Machlup Method, Porat Method, AHP method, and Factor Analysis method are common methods in such researches. DEA method needs lesser indices than other methods discussed above to evaluate the efficiency of AI and overcome the shortage of data collecting difficulty.

\section{Methodology}

\subsection{CCR Model}

Data envelopment analysis (DEA) is a nonparametric method in operations research and economics for the estimation of production frontiers [8]. It is used to empirically measure productive efficiency of decision making units (or DMUs). Non-parametric approaches have the benefit of not assuming a particular functional form/shape for the frontier, however they do not provide a general relationship (equation) relating output and input [9].

CCR Model is one basic DEA model. CCR Model is proposed by Charnes, Cooper and Rhodes in 1978.

$$
\text { (D1) }\left\{\begin{array}{c}
\min \theta=V_{D_{1}} \\
\text { s.t. } \\
\sum_{k=1}^{n} X_{k} \lambda_{k}+s^{-}=\theta X_{t} \\
\sum_{k=1}^{n} X_{k} \lambda_{k}-s^{+}=Y_{t} \\
\sum_{k=1}^{n} X_{k} \lambda_{k}-s^{+}=Y_{t} \\
s^{+} \geq 0, s^{-} \geq 0
\end{array}\right.
$$

In D1, set $\mathrm{X}_{\mathrm{l}}=\left(\mathrm{x}_{11}, \mathrm{x}_{21}, \cdots, \mathrm{x}_{\mathrm{ml}}\right), \mathrm{Y}_{\mathrm{l}}=\left(\mathrm{y}_{11}, \mathrm{y}_{21}, \cdots, \mathrm{y}_{\mathrm{sl}}\right)$.

Description of CCR Efficiency Model:

1) Suppose there are $n D M U_{s}: D M U_{1}, D M U_{2}, \ldots$, and $D M U_{n}$.

2) Suppose $m$ input items and $s$ output items are selected with the properties.

3) Let the input and output data for $\mathrm{DMU}_{\mathrm{j}}$ be $\left\{\mathrm{x}_{1 \mathrm{j}}, \mathrm{x}_{2 \mathrm{j}}, \cdots, \mathrm{x}_{\mathrm{mj}}\right)$ and $\left(\mathrm{y}_{1 \mathrm{j}}, \mathrm{y}_{2 \mathrm{j}},---, \mathrm{y}_{\mathrm{sj}}\right)$

4) The calculation of total efficiency of $\mathrm{DMU}_{1}$ can be changed to linear programming problem in next slide. 
5) Let $\mathrm{Xl}=\left(\mathrm{x}_{11}, \mathrm{x}_{21}, \cdots, \mathrm{x}_{\mathrm{ml}}\right), \quad \mathrm{Yl}=\left(\mathrm{y}_{11}, \mathrm{y}_{21},---, \mathrm{y}_{\mathrm{sl}}\right)$

6) We assume the return scale in CCR Model is not changed.

7) $\theta$ is the efficiency rate, $\theta$ is at most $1(0 \leqslant \theta \leqslant 1)$

Economy Meaning of $\theta$ : when the output $\mathrm{Y}$ is alternative by $\mathrm{k}$ DMUs output with a linear combinations, $\theta$ is the compressibility of its input $\mathrm{X}, \theta$ is also known as the efficiency rate value.

1) If $\theta=1$, the DMU being examined is the point of being efficient frontier surface, and it is efficient status.

2) If $\theta<1$, the DMU being examined is invalid status, 1- $\theta$ is the more input of the DMU being examined than efficient status.

DEA efficient economic meaning: output can't be any increased unless one or more inputs to increase or reduce other types of output. Under the same condition, input can't be any decreased.

\subsection{Super-efficiency DEA Model}

When there are many DMUs which are efficient and their efficiency of evaluation is $1(\theta=1), \mathrm{CCR}$ model can't tell which is better among these DMUs. Anersen (1993) proposed the super-efficiency DEA model to sort efficient DMUs and give them ranking.

$$
\left(D_{2}\right)\left\{\begin{array}{c}
\min \theta=V_{D_{2}} \\
\text { s.t. } \\
\sum_{\substack{n=1 \\
k \neq 1 \\
n}}^{n} X_{k} \lambda_{k}+s^{-}=\theta X_{t} \\
\sum_{\substack{k=1 \\
k \neq 1}} X_{k} \lambda_{k}-s^{+}=Y_{t} \\
\lambda_{k} \geq 0, k=1,2, \cdots, n \\
s^{+} \geq 0, s^{-} \geq 0
\end{array}\right.
$$

\subsection{Enovation in Super-efficiency DEA Model Compare with CCR Model}

Super-efficiency DEA Model: in the process of evaluating $\mathrm{DMU}_{1}$ efficiency, the inputs and outputs of $\mathrm{DMU}_{1}$ are alternated by the linear combination of inputs and outputs of the other DMUs excluding themselves.

CCR model: in the process of evaluating $\mathrm{DMU}_{1}$ efficiency, all inputs and outputs, including the inputs and outputs of themselves as part of the calculation.

An efficient decision-making unit can make it into a pro-rata increase, while the efficiency of the value does not change, the proportion of its investment increased is the super-efficiency evaluation value.

\section{Data}

Using the DEA and Super-efficient DEA model to evaluate the inputs and outputs of agricultural informatization (AI) in Huaihua and Xiangxi based on the data from 2009 to 2013 collected from statistical bulletin of national economic and social development in Hunan Province, We can analysis 
the data of inputs and outputs of agricultural informatization in two areas, and find out the aspects which can be improved in AI investment, also we can figure out the tendency of AI in two areas.

We built an index system containing 9 indices in concern of the feasibility and accuracy, and the data is collected from statistical bulletin of national economic and social development published by Statistical Bureau of Hunan Province.

In the index system, Y1 means "Added Value of Agriculture(Billion Yuan)", Y2 means "Farmers' Per Capita Income(Yuan)", X1 means "Main Business Volume of Post(Billion Yuan)", X2 means "Electricity for Rural Use(Million kWh)", X3 means "Rural Telephone Subscribers(Million)", X4 means "Cell phone Subscribers(Million)", X5 means "Rural TV Coverage(\%)", X6 means "Rural Radio Coverage (\%)", X7 means "Internet Accounts(Million)".

Data about invest and output of $\mathrm{AI}$ in Huaihua and Xiangxi is listed in table 1:

Table 1. Data about invest and output of Agricultural Informatization in Huaihua and Xiangxi

\begin{tabular}{ccccccccccccc}
\hline City & Year & Y1 & Y2 & X1 & X2 & X3 & X4 & X5 & X6 & X7 \\
\hline Huaihua & 2009 & 4.602 & 2905 & 4.246 & 0.184 & 0.808 & 1.6246 & $97.1 \%$ & $91.5 \%$ & 0.145 \\
& 2010 & 5.291 & 3520 & 5.833 & 0.211 & 0.7217 & 2.048 & $97.5 \%$ & $91.5 \%$ & 0.2144 \\
& 2011 & 5.52 & 3573 & 2.511 & 0.228 & 0.602 & 2.335 & $98.0 \%$ & $92.8 \%$ & 0.242 \\
& 2012 & 8.16 & 4701 & 2.743 & 0.3127 & 0.575 & 2.6395 & $98.5 \%$ & $93.1 \%$ & 0.3215 \\
& 2013 & 8.3 & 5849 & 3.001 & 0.3441 & 0.4834 & 3.0664 & $98.5 \%$ & $93.3 \%$ & 0.3604 \\
Xiangxi & 2009 & 6.23 & 2858 & 2.797 & 0.2492 & 0.3178 & 0.9856 & $92.0 \%$ & $89.0 \%$ & 0.0993 \\
& 2010 & 6.51 & 3173 & 3.421 & 0.2604 & 0.2882 & 1.1153 & $93.8 \%$ & $72.9 \%$ & 0.138 \\
& 2011 & 6.934 & 3674 & 1.382 & 0.27736 & 0.272 & 1.0114 & $94.5 \%$ & $73.5 \%$ & 0.1702 \\
& 2012 & 7.22 & 4229 & 1.526 & 0.2888 & 0.2537 & 1.229 & $95.5 \%$ & $87.0 \%$ & 0.1996 \\
& 2013 & 7.45 & 5260 & 1.64 & 0.298 & 0.24 & 1.293 & $95.7 \%$ & $97.0 \%$ & 0.231 \\
\hline
\end{tabular}

\section{Empirical Results and Discussion}

The data was processed by DEAP (Data Envelopment Analysis Program, Version 2.1) using CCR model, the results are listed in table2. And we also used EMS software (Efficiency Measurement System, Version 1.3) using to process the data with Super-efficiency CCR model, the results are listed in table3.

Table 2. DEA value of AI in Huaihua and Xiangxi (2009-2013)

\begin{tabular}{ccccccccc}
\hline \multirow{2}{*}{ Year } & \multicolumn{2}{c}{ CRSTE } & \multicolumn{2}{c}{ VRSTE } & \multicolumn{2}{c}{ SCALE } & \multicolumn{2}{c}{ SCALE MERIT } \\
\cline { 2 - 8 } & Huaihua & Xiangxi & Huaihua & Xiangxi & Huaihua & Xiangxi & Huaihua & Xiangxi \\
\hline 2009 & 0.999 & 1.000 & 1.000 & 1.000 & 0.999 & 1.000 & increase & - \\
2010 & 1.000 & 1.000 & 1.000 & 1.000 & 1.000 & 1.000 & - & - \\
2011 & 0.968 & 1.000 & 1.000 & 1.000 & 0.968 & 1.000 & increase & - \\
2012 & 1.000 & 1.000 & 1.000 & 1.000 & 1.000 & 1.000 & - & - \\
2013 & 1.000 & 1.000 & 1.000 & 1.000 & 1.000 & 1.000 & - & - \\
Average & 0.993 & 1.000 & 1.000 & 1.000 & 0.993 & 1.000 & & \\
\hline
\end{tabular}

In table 2, CRSTE means "technical efficiency from CRS DEA", VRSTE means "technical efficiency from VRS DEA", SCALE means "scale efficiency = CRSTE / VRSTE". 
Table 3. Super-efficiency DEA value of AI in Huaihua and Xiangxi (2009-2013)

\begin{tabular}{ccccc}
\hline Year & Huaihua & Rank & Xiangxi & Rank \\
\hline 2009 & $128.58 \%$ & 2 & $133.00 \%$ & 1 \\
2010 & $101.97 \%$ & 4 & $104.12 \%$ & 5 \\
2011 & $99.76 \%$ & 5 & $116.01 \%$ & 3 \\
2012 & $114.02 \%$ & 3 & $107.65 \%$ & 4 \\
2013 & $203.68 \%$ & 1 & $131.48 \%$ & 2 \\
\hline
\end{tabular}

Based on the data in table 3 , we can figure out the tendency of agricultural informatization in Huaihua and Xiangxi areas.

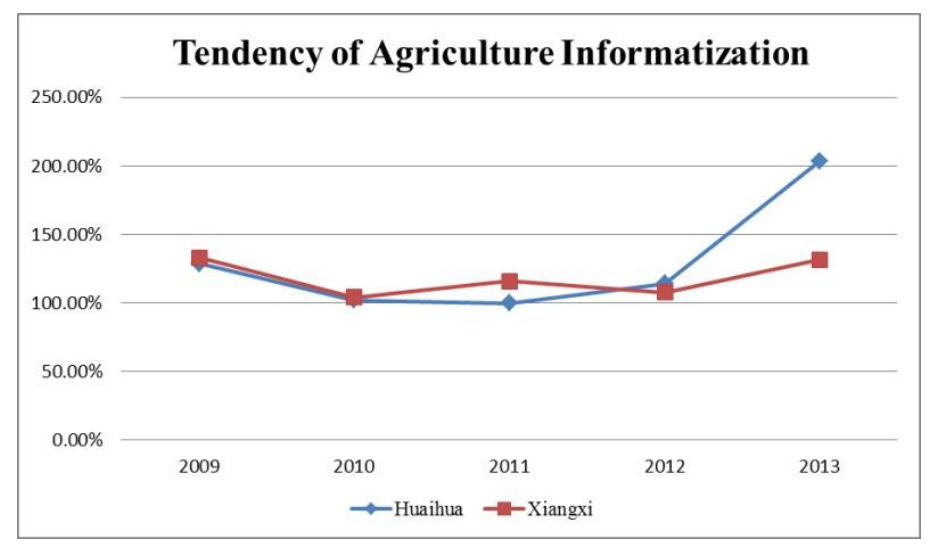

Fig. 1. Tendency of AI in Huaihua and Xiangxi

\subsection{Results Analysis in table 2}

1) The results of CRSTE, VRSTE and SCALE are 1 in 2010, 2012 and 2013, which means the inputs and outputs about $\mathrm{AI}$ in these years are reasonable, and they are in efficient status.

2) The CRTES values of Huaihua in 2009 and 2011 are below 1, but greater than 0.9, which means the inputs and outputs about AI in these years have spaces of improving.

3) The scale merit of Huaihua increased in 2009 and 2011, which means the technical efficiency from CRS DEA is increased by expand the scale of AI investment.

\subsection{Results Analysis in table 3 and figure 1}

1) In 2011, it is inefficient considering the inputs and outputs in AI in Huaihua.

2) From 2010 to 2013, the efficiency of AI in Huaihua is gradually increased, but the efficiency in Xiangxi is relatively gentle and does not changed so much.

3) The efficiency from 2009 to 2010 in both areas is decreased, but the reasons are different. The increase of electricity for rural use leads to the decrease of efficiency in Huaihua, however, the decrease of rural radio coverage leads to the decrease of efficiency in Xiangxi. 


\subsection{Discussion}

The efficient status $(\theta=1)$ does not means developed status or developing rapidly of AI, but only tell us that considering the output in those years, the inputs is not redundant.

Even the efficiency status of AI in Xiangxi is efficient, the developed degree in this area is lower than Huaihua, which can be seen from the data in table 1.

If we want to describe the development status of $\mathrm{AI}$ in undeveloped areas, more indices should been take into account in statistical bulletin.

\section{Conclusions}

The CCR model and Super-efficiency CCR Model are suitable to describe whether there any redundancy comparing inputs with outputs in AI, but can't figure out the development level of AI.

The index system can be modified better if more indices data is collected, and describe the efficiency of inputs and outputs comprehensively.

Even the efficiency status of AI in the two areas is efficient, the developing level of AI is still low, especially in the popularity rate of Internet.

\section{Acknowledgment}

Fund for this paper was provided by MOE (Ministry of Education in China) Project of Humanities and Social Sciences (Project No. 12YJA630123). Research in this paper is also supported by School of Information Engineering, Minzu University of China, Beijing.

\section{References}

1. Rogers, Everett M. Informatization, globalization, and privatization in the new millennium. The Asian Journal of Communication [J], 2000, 10(2):71-92.

2. http://wiki.mbalib.com/wiki, browsed in May10, 2014.

3. Zhang Lingxian, \&etc. Evaluation of the rural informatization level in four Chinese regions- A methodology based on catastrophe theory, Mathematical and Computer Modeling [J], 2013, 58: 868-876.

4. Liu Yunwen, Ge Jingmin. Informatization Measurement Theories Comparative Study in Domestic and Foreign. Information Studies: Theory \& Application [J], 2004, 2:144-147 (in Chinese).

5. Wei Zhiyu, Yang Zhongzhi. Study on Rural Information Undertaking Public Satisfaction Index Model. Information Science [J], 2008, 2: 278-283 (in Chinese) .

6. Chen Liyu, Ye Ji. Analysis on the Agricultural Expenditure of County Finance in the Transformation of Agricultural Modernization. Journal of Jilin Agricultural University [J], 2012(2):230-236 (in Chinese).

7. Liang Chunyang. The construction of Agricultural Information Service Performance Evaluation System. Library Theory and Practice [J], 2012, 9:31-35 (in Chinese).

8. Charnes, A., W. Cooper, \& E., Rhodes. Measuring the Efficiency of Decision-making Units. European Journal of Operational Research [J], 1978, 2:429-444.

9. Aristovnik, A., et al. Relative efficiency of police directorates in Slovenia: A non-parametric analysis. Expert Systems with Applications: An International Journal, 2013, 40(2): 820-827. 